\title{
EXPLORING BARRIERS TO ADOPTION OF MOBILE PAYMENTS FOR UNIVERSITY STUDENTS: LACK OF AWARENESS, LACK OF AVAILABILITY, AND PERCEIVED SECURITY RISKS
}

\author{
Jamie L. Pinchot, Robert Morris University University, pinchot@rmu.edu \\ Sushma Mishra, Robert Morris University,mishra@rmu.edu \\ Karen L. Paullet, Robert Morris University, paullet@rmu.edu \\ Frederick G. Kohun, Robert Morris University,kohun@rmu.edu
}

\begin{abstract}
Though mobile technology has become common in everyday life, the adoption of mobile payments (m-payments) is not high, despite the fact that technologically advanced solutions for mobile payments exist. This paper investigates barriers to consumer adoption of mobile payment services, including lack of awareness, lack of availability, and perceived security risks. A survey was administered to 136 participants and found statistically significant relationships between each of these barriers and intention to use mobile payments.
\end{abstract}

Keywords: Mobile Payments, Mobile, Mobile Devices, M-Payments, Chi Square, Security Risks, Survey

\section{INTRODUCTION}

Mobile devices have become an integral part of today's social, cultural and personal experience. With a greater penetration of smartphones in every household, the usage of mobile devices in terms of accessing social media, watching videos, and playing games and using other apps for entertainment has gone up dramatically. Given the growth in usage of mobile devices, the percentage of consumers who use mobile payments frequently is still low (Ewing, Leberman, Mendelsohn, \& Milner, 2012).

Mobile payment services can be defined as the use of a mobile device to conduct a payment transaction in which money is transferred either directly or via an intermediary from a payer to a receiver (Dahlberg, Mallat, Ondrus, \& Zmijewska, 2008; Mallat, 2007). This broad definition includes mobile banking services, which entail access to traditional banking services from established banks via a mobile device or mobile app. However, a distinction should be made between mobile banking services and mobile payments. Mobile banking services are typically reliant on existing systems available at banks and are made available to a bank's own customers (Mallat, 2007). In contrast, mobile payments are offered by third-party providers that provide the technological means to facilitate payments by connecting to a payer's bank, credit card, or other electronic funding source from a mobile device in order to transfer funds to a receiver. A mobile payment (m-payment) then, for the purpose of this paper, is the use of a mobile device to make purchases in physical or online stores; such purchases might include goods, services, digital content, and fund transfers (Loilier, 2013).

The total number of cellular service subscriptions has reached an all-time high to almost six billion by the end of 2011 which is equal to a global penetration of $86 \%$, or 86 devices per 100 human beings on earth, over the age of five (Loilier, 2013). Out of these six billion, at least $20 \%$ of users utilize mobile broadband connections that allow them to use complex data-based transactions in a secure manner. These broadband connections are growing at the rate of 45\% per year (Loilier, 2013). Though mobile technology has become common in everyday life, the adoption of mobile payments (m-payments) is not high, despite the fact that technologically advanced solutions for $\mathrm{m}$ payments exist. A survey conducted by the U.S. Federal Reserve Board indicated that only twenty-two percent of all mobile phone owners reported having made a mobile payment during 2014 (Consumers and mobile, 2015). According to MasterCard research, no country has achieved huge consumer acceptance in terms of mobile payment adoption and these are still the early days for this technology (MasterCard, 2014). 
Mobile payment providers consist of a variety of competing groups including banks, telecom operators, technology companies such as Apple and Google, and other privately owned companies, such as Starbucks. They must handle challenges in standardization and compatibility in order to appeal to a variety of consumers using many different types and models of mobile devices. The challenge of managing mobile payments technology meant to work on a variety of mobile devices with different hardware and software is a daunting one. In addition, mobile payment providers must deal with two distinct and demanding groups of adopters, consumers and merchants (Mallat, 2007). This makes for a complex and challenging environment. However, there are indicators to suggest that consumers are willing to engage in adopting this technology (Jia et al., 2015). More research to understand the drivers of this acceptance is warranted.

In order to exploit the benefits of mobile payment innovations, it is important that consumers use this technology more and companies are able to recover their investments. It is important to investigate the barriers that stop consumers from adopting and using mobile payment options more in day-to-day life. The goal of this study is to investigate barriers that impede the adoption of mobile payments. The specific research questions that this study addresses are:

RQ1: What barriers impact consumer adoption of mobile payments?

RQ2: What can be done to address these barriers and encourage consumer adoption of mobile payments?

The remaining paper is organized in the following way. The introduction section is followed by a critical analysis of research literature in the area of barriers to adoption in mobile payment services. The methodology section presents data collections strategies and a description of how the data was analyzed. The findings from the survey are presented in a results section. A discussion section that lists the implications, limitations and future research areas related to this study notes the conclusions that were drawn.

\section{LITERATURE REVIEW}

\section{Factors Affecting Adoption of Mobile Payments}

Studies on mobile payments (m-payments) can be broadly classified into two categories: adoption and system impact with consumers and use of such systems in social, economic, and cultural context (Wang, 2012). This study is focused on the perspective of mobile phone users on barriers in accepting mobile payment systems.

In the adoption and system impact of users' stream of research, the Technology Acceptance Model (TAM) has been used extensively in m-payment adoption studies. In a study conducted by Jia et al. (2015) to understand the adoption of mobile payments, the researchers found that consumers with exposure to mobile payments are likely to search for information about mobile payments. They also argue that exposure to mobile payments and consumers' information search increases the trust in mobile payments. The trust in mobile payments is more important for non-users than for users in encouraging them to use mobile payments (Jia et al., 2015). Daştan and Gürler (2016), in a study to understand adoption of mobile payment systems, found that there is a negative relationship between environmental risk and perceived trust, and also a positive relationship between firm reputation and perceived trust, in the context of adoption of mobile payments. The authors argue that environmental risk and firm reputation are associated with trust. The results of this study did not show any significant effect between the perceived ease of use and adoption of mobile payments. Jia et al. (2014), in a study assessing the effect of technology usage habits on consumers' intention to continue use mobile payments, present a set of habits or behaviors that would enhance or positively impact usage of mobile payments. These are: consumers' online shopping habits, consumers' mobile services (such as text messaging using Short Message Service (SMS), entertainment, etc.) and consumers' cell phone usage habits.

Individual differences and characteristics of mobile payment systems affect the intention of usage (Kim et al., 2010). Individual differences include knowledge of the system and mobile payments. System characteristics include convenience, compatibility and reachability of the system, within the above study (Kim et al., 2010). Trust and perceived risk also affect consumer acceptance of mobile payment systems through perceived usefulness and perceived ease of use (Chandra et al., 2010; Shin, 2010). Consumers are likely to adopt mobile payment services if 


\section{Issues in Information Systems \\ Volume 17, Issue III, pp. 20-30, 2016}

they feel that their beliefs and behavioral pattern are aligned with usage expectations. It also suggested that perceived usefulness and perceived security of mobile payment methods positively impacts the customers' intention of using mobile payments. Subjective norm in terms of influence of peer groups has a positive impact on mobile payment usage. The study did not find a relationship between perceived ease of use and consumers' intention to use mobile payments in restaurants.

Mallat (2007) conducted a qualitative study of consumer adoption of mobile payment systems and identified several barriers to the adoption of mobile payments, including perceived risks, premium pricing for payments made through mobile services, complexity of payment procedures, low adoption rates, perceived incompatibility with large value purchases, and lack of merchant acceptance. Findings indicated that perceived risks of using mobile payments were reduced when there was trust in mobile payment service providers and merchants, suggesting that more reliable service providers have an advantage over smaller competitors.

Cyril et al. (2008) examined security factors influencing the acceptance of mobile payment systems in Malaysia. Their findings looked at the impact of trust and how it influenced users' intention to use mobile payment services. The issue of security emerged as a major barrier to acceptance of mobile payments.

\section{Security of Mobile Payments}

Mobile payments involve contactless transactions. This typically means that mobile device is held near a receiving sensor at point of sale, and a wireless communication transmission occurs between the mobile device and the sensor. Several technologies are available for mobile payments at point of sale (POS). Near field communication (NFC) is the best known among them, and enables wireless communication between mobile devices at short distances. Apple Pay and Google Wallet (offered by Apple and Google, respectively) both use NFC technology for their mobile payment applications (Bonderud, 2015; Hayashi, 2012). Radio frequency identification (RFID) is another technology that has been widely used for mobile payments. RFID is similar to NFC but uses radio waves and thus allows for a farther transmission range. Wireless Application Protocol (WAP) enables access to the Internet from a mobile device. Additional apps, including WAP browsers, can be installed on a mobile device and used to make electronic payments (Hayashi, 2012).

When innovative technologies such as contactless mobile payments are adopted, security becomes a vital issue (Loilier, 2013). There is a common consumer perception that mobile payments are insecure (Cyril et al., 2008). In mobile payment transactions, credit card number and care verification value code (CVV) are often transmitted. Wireless networks are vulnerable to attacks and mobile encryption systems are less robust than traditional encryption systems (Misra \& Wickamasinghe, 2004). These security concerns increase users' perceived risk and decrease their usage intention toward such systems (Zhou, 2011). Though some security practices are in place, primarily using cryptography, there are no clear standards on protection of payment card information in such transactions from regulatory bodies.

Due to a lack of regulation and standards, different mobile payment vendors have varying levels of security. One of the more popular mobile payment apps, Apple Pay, has been touted as one of the most secure (Sacco, 2014). In addition to using NFC to transmit data, Apple Pay uses a form of tokenization to protect user data (Apple, 2016; Bonderud, 2015). For Apple Pay, payment cards entered into the app are sent to Apple in an encrypted format. Once received, decrypted, and registered by Apple, the card information is then re-encrypted with a unique Device Account Number. Each time a payment is made at point of sale, this Device Account Number and a transactionspecific dynamic security code (for one-time use) is the only data that is transmitted from the mobile device to the merchant (Apple, 2016). A cashier will never see a credit card number, name, or other personally identifiable information. Since a merchant does not ever receive a credit card number, and each dynamic security code can only be used once, this effectively protects Apple Pay users from merchant security breaches involving leaked credit card numbers (Sacco, 2014). For additional security, Apple Pay requires that users have a passcode enabled on their mobile device to protect it from authorized access in the case of loss or theft of the device, and also utilizes Apple's Touch ID fingerprint scanner; when a user attempts to pay with Apple Pay, they must authenticate with a fingerprint during the transaction (Apple, 2016). These security features are considered by some security experts to be safer and more secure than using a credit card at point of sale (Sacco, 2014). Android Pay, another popular mobile 
payment app, also uses NFC to transmit data and employs tokenization to protect user data, transmitting a virtual account number in lieu of a credit card number for payment transactions. However, Android Pay does not require fingerprint authentication for transactions (Android, 2016).

It is clear that establishing users' trust in mobile payment systems and reducing their level of perceived risk for such systems would help in adoption of mobile payment systems. Mobile phone users need motivation to form positive perceptions about mobile payments. There is a big opportunity for mobile marketers to develop this perception through pushing positive messages about this experience to consumers and reaching out to them (Wang, 2006).

In summary, the literature suggests that mobile payment systems have barriers in adoption of this technology in terms of lack of awareness, poor ease of use, lack of availability, and concerns regarding perceived security risks. As ease of use has been addressed in multiple previous studies, this study will explore lack of awareness, lack of availability, and perceived security risks.

\section{RESEARCH METHODOLOGY}

This exploratory study sought to identify and further understand the barriers that discourage consumer adoption of mobile payments (m-payments). A web-based survey was distributed to a convenience sample of undergraduate and graduate students at a mid-Atlantic university in April 2016. The survey collected demographic data from participants, including age, gender, education level, and household income. Next, participants were asked how long they have been using a smartphone (with the option to note if they have never used one). If participants have used a smartphone, they were then asked to indicate the type of smartphone that they primarily use (e.g. Android, iPhone, Windows Phone, BlackBerry, other). Then, participants were asked to note the types of apps that they regularly use on their smartphone (e.g. news, entertainment, social media, shopping, banking/financial, other).

After these demographics and usage statistics for mobile devices, the questionnaire delved into awareness and usage issues regarding mobile payments. Participants were asked if they were aware that there are apps that can be used on a smartphone to make purchases in place of a credit or debit card. A definition was then offered:

Mobile payment services offer the ability to pay for purchases using your smartphone as an alternative to a credit or debit card. Typically you download an app to your smartphone and the app is loaded with your banking, credit card, or debit card information. You then use the app to pay for a purchase at a retailer by opening the app on your smartphone and tapping it to the payment device at a cash register instead of swiping your card.

Following this definition, participants were asked if they have ever used a mobile payment service to make a purchase. They were also asked if they were familiar with specific mobile payment services, to be selected from a list of popular m-payments apps including: Apple Pay, Android Pay, Google Wallet, Samsung Pay, Current C, Square Cash, Starbucks Mobile App, Venmo, LevelUp, Dwolla, and other (with space to indicate an m-payment app not included in the list). To indicate intention to use, participants were also asked to indicate, on a five-point Likert scale, how likely they would be to use mobile payments in the future.

The next set of questions was targeted toward understanding specific barriers addressed by the research questions that might impede participants' adoption of mobile payments, based on the review of the literature. These barriers included lack of awareness of awareness, lack of availability, and perceived security risks. Participants were asked to respond to three statements for each of the four barriers on a five-point Likert scale. The statements for each barrier category were adapted from a study conducted on Consumers and Mobile Financial Services (Consumers and Mobile, 2015). An additional, similar statement that used negative (reverse) wording was added to each category in order to double-check that the results were valid. The questionnaire was piloted with 20 adults prior to distribution in order to ensure reliability and validity, and small wording changes were made as necessary to reduce ambiguity.

One open-ended question was also included, asking participants what would encourage them to use mobile payments in the future. Data was exported from the web-based survey tool into SPSS for data analysis. The data 
was inspected for completeness and negatively worded questions were recoded to opposite values for accurate reporting of results.

\section{RESULTS}

A total of 136 participants completed the questionnaire. The sample had more males (68\%) than females (32\%) and these demographics are shown in Table 1.

Table 1. Number and Percentage of Participants by Gender

\begin{tabular}{|l|c|c|}
\hline \multicolumn{1}{|c|}{ Gender } & \# of Participants & $\begin{array}{c}\text { Percentage of Sample } \\
(\mathbf{n = 1 3 6 )}\end{array}$ \\
\hline Female & 43 & $32 \%$ \\
\hline Male & 93 & $68 \%$ \\
\hline
\end{tabular}

In terms of age, the sample was heavily weighted with younger participants, as shown in Table 2, with the 18-25 year old range accounting for $67 \%$. The $26-40$ age range made up $26 \%$ and the $41-55$ range included the final $7 \%$ of the sample. Because the survey was administered to college students, this could easily account for the high number of younger participants.

Table 2. Number and Percentage of Participants by Age Groups

\begin{tabular}{|l|c|c|}
\hline \multicolumn{1}{|c|}{ Age } & \# of Participants & $\begin{array}{c}\text { Percentage of Sample } \\
(\mathbf{n = 1 3 6})\end{array}$ \\
\hline $18-25$ & 91 & $67 \%$ \\
\hline $26-40$ & 36 & $26 \%$ \\
\hline $41-55$ & 9 & $7 \%$ \\
\hline 56 or older & 0 & $0 \%$ \\
\hline
\end{tabular}

Participants in the sample reported high levels of experience using smartphones. Twenty-nine percent (29\%) of the participants had used a smartphone for 7 years or more, $49 \%$ for 4 to 6 years, $19 \%$ for 1 to 3 years, $1 \%$ for 6 to 12 months, and $1 \%$ for less than 6 months. One percent (1\%) indicated that they have never used a smartphone.

In terms of smartphone operating systems chosen, the sample was skewed toward iOS (Apple) and Android (Google). The majority of the participants, 55\%, indicate that they primarily use an iPhone, and $40 \%$ use Android. One percent (1\%) use BlackBerry, $0 \%$ use Windows Phone, and 2\% noted that they do not use a smartphone. An additional $2 \%$ indicated Other. In terms of how participants use smartphones, $43 \%$ indicated that they use their device to access news, $65 \%$ for entertainment, $82 \%$ for social media, $74 \%$ for text messaging / Short Message Service (SMS), $30 \%$ for academics research, $23 \%$ for office productivity, $63 \%$ for online banking, and $43 \%$ for online shopping.

Participants in the sample were generally aware of mobile payments, with $88 \%$ responding that they were aware of the existence of mobile payment services, and $12 \%$ indicating that they were unaware. Participants were then asked to select each of the m-payment services that they might be familiar with (exposure to the service in some capacity). Apple Pay was the most widely known m-payment service, with $69 \%$ of the sample noting familiarity with it. Google Wallet was second in terms of exposure, at $40 \%$. Android Pay was known by $40 \%$ of participants and Samsung Pay by $32 \%$. Thirty-two percent (32\%) indicated familiarity with Starbucks' mobile payments app, which is used only at Starbucks coffee shops. Sixteen percent (16\%) were familiar with Square Cash, and 15\% were familiar with Venmo, the m-payments app offered by PayPal. Additionally, three participants chose Other and all three of them wrote in PayPal as a selection. PayPal is not typically considered an m-payments app, but rather is used for traditional online purchases and money transfers. However, from this response, it appears that PayPal is 
well known for digital payments and perhaps this indicates that their mobile app Venmo will continue to increase in market share in the m-payments industry as more consumers become familiar with it and recognize it as a service of PayPal. Two other m-payments services, LevelUp and Dwolla, were not selected by any of the participants.

When asked about usage of mobile payments, $36 \%$ of participants in the sample responded that they had used mobile payments in the past. Sixty-four percent $(64 \%)$ had never used m-payments. Intention to use mobile payments in the future was well-distributed within the sample, with $12 \%$ extremely likely to use m-payments in the future, $30 \%$ likely to use, $25 \%$ remaining neutral, $21 \%$ unlikely to use, and $12 \%$ extremely unlikely to use mpayments, as shown in Figure 1.

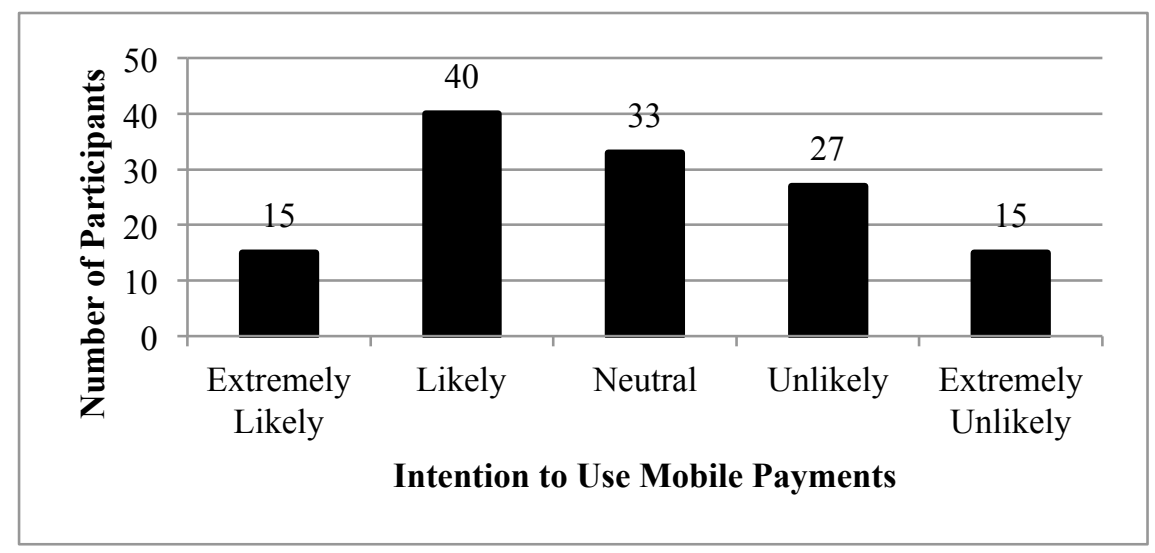

Figure 1. Participants' Intention to Use Mobile Payment Services

To measure awareness of mobile payments, participants were asked to respond to three statements and indicate their level of agreement. Two of the statements were negatively worded on the survey and then recoded and reworded positively during data analysis. Each of the following statements addresses lack of awareness, and participant responses are shown in Table 3.

Table 3. Lack of Awareness of Mobile Payments

\begin{tabular}{|c|c|c|c|c|c|c|}
\hline \multicolumn{2}{|c|}{$x^{2}$} & \multicolumn{5}{|c|}{ Percentage } \\
\hline Survey Item & Variable & $\begin{array}{c}\text { Strongly } \\
\text { Agree }\end{array}$ & Agree & Neutral & Disagree & $\begin{array}{l}\text { Strongly } \\
\text { Disagree }\end{array}$ \\
\hline $\begin{array}{l}\text { I am not aware of mobile payment } \\
\text { services that are available for use on my } \\
\text { smartphone }\end{array}$ & AWARE_1 & $51 \%$ & $33 \%$ & $10 \%$ & $4 \%$ & $2 \%$ \\
\hline $\begin{array}{l}\text { I don't really understand all the different } \\
\text { mobile payment options }\end{array}$ & AWARE_2 & $6 \%$ & $29 \%$ & $31 \%$ & $25 \%$ & $9 \%$ \\
\hline $\begin{array}{l}\text { I don't know how to use mobile payment } \\
\text { services on my smartphone }\end{array}$ & AWARE_3 & $26 \%$ & $31 \%$ & $22 \%$ & $17 \%$ & $4 \%$ \\
\hline
\end{tabular}

These responses indicate that while the sample indicated a general awareness of the existence of mobile payment services (see previous results in this section), the majority of participants do not seem to be aware of the types of features or services that can be used on their own smartphones and/or how to use those services. In addition, there was a relatively even distribution of responses indicating that some participants do feel that they understand all of the different mobile payment options while others do not. Categories were collapsed, combining Strongly Agree with Agree, and Strongly Disagree with Disagree. A Pearson chi-square test indicated that there is a statistically significant relationship $(\mathrm{p}<.05)$ between AWARE_2 (I don't really understand all the different mobile payment options) and intent to use mobile payments (chi-square $=12.659, \mathrm{df}=4, \mathrm{p}=.013$ ). In addition, a Pearson chi-square test indicated that there is a strong, statistically significant relationship $(\mathrm{p}<.01)$ between AWARE_3 (I don't know how to use mobile payment services on my smartphone) and intent to use mobile payments (chi-square $=14.319$, $\mathrm{df}$ 
$=4, \mathrm{p}=.006)$. When asked what would encourage them to use m-payments in the future, 7 of the 79 participants (9\%) who responded to the open-ended question indicated in some way that they need more training or information about mobile payments before they would feel comfortable using them. Some examples of participant responses included "I think I just need to gain a basic understanding of how mobile payment services work" and "More knowledge on how they work and how to use them", and "I would need to study them more in-depth to feel comfortable using them." Overall, these results suggest an overall lack of awareness in regard to m-payments within the sample and suggest that lack of awareness of m-payments, and in particular, awareness of specific services and features available for their smartphone, is a barrier to adoption of mobile payments.

To measure availability of mobile payments, participants were asked to respond to three statements and indicate their level of agreement. One of the statements was negatively worded on the survey and then recoded and reworded positively during data analysis. Each of the following statements addresses lack of availability, and participant responses are shown in Table 4.

Table 4. Lack of Availability of Mobile Payments

\begin{tabular}{|c|c|c|c|c|c|c|}
\hline & & \multicolumn{5}{|c|}{ Percentage } \\
\hline Survey Item & Variable & $\begin{array}{c}\text { Strongly } \\
\text { Agree }\end{array}$ & Agree & Neutral & Disagree & $\begin{array}{l}\text { Strongly } \\
\text { Disagree }\end{array}$ \\
\hline $\begin{array}{l}\text { I do not think mobile payments are } \\
\text { accepted by enough retailers to make } \\
\text { their use worthwhile }\end{array}$ & AVAIL_1 & $4 \%$ & $20 \%$ & $39 \%$ & $25 \%$ & $12 \%$ \\
\hline $\begin{array}{l}\text { The places I shop don't accept mobile } \\
\text { payments }\end{array}$ & AVAIL_2 & $5 \%$ & $21 \%$ & $52 \%$ & $19 \%$ & $3 \%$ \\
\hline $\begin{array}{l}\text { I do not have the necessary feature on } \\
\text { my phone to use mobile payment } \\
\text { services }\end{array}$ & AVAIL_3 & $4 \%$ & $7 \%$ & $18 \%$ & $41 \%$ & $30 \%$ \\
\hline
\end{tabular}

Responses to these statements include high percentages in the neutral category. This may suggest that many participants in the sample feel uncomfortable responding to these statements, perhaps due to a lack of knowledge regarding where mobile payments are available. Categories were collapsed, combining Strongly Agree with Agree, and Strongly Disagree with Disagree. A Pearson chi-square test indicated that there is a strong, statistically significant relationship $(\mathrm{p}<.01)$ between AVAIL_1 (I do not think mobile payments are accepted by enough retailers to make their use worthwhile) and intent to use mobile payments (chi-square $=13.615, \mathrm{df}=4, \mathrm{p}=.009$ ). When asked what would encourage them to use m-payments in the future, 22 of the 79 participants (28\%) who responded to the open-ended question indicated in some way that they would use mobile payments if they became available for use at more retail locations. For example, one participant noted, "I would use the features more if they start to be accepted in more locations." Another participant responded, "Wider acceptance and promotion by retailers." These findings are consistent with previous literature that also suggests that lack of availability of mobile payment services could be a barrier to acceptance (Kim et al., 2010; Mallat, 2007).

To measure perceived security risks of mobile payments, participants were asked to respond to three statements and indicate their level of agreement. One of the statements was negatively worded on the survey and then recoded and reworded positively during data analysis. Each of the following statements addressed perceived security risks, and participant responses are shown in Table 5. 
Table 5. Perceived Security Risks of Mobile Payments

\begin{tabular}{|c|c|c|c|c|c|c|}
\hline & & \multicolumn{5}{|c|}{ Percentage } \\
\hline Survey Item & Variable & $\begin{array}{c}\text { Strongly } \\
\text { Agree }\end{array}$ & Agree & Neutral & Disagree & $\begin{array}{l}\text { Strongly } \\
\text { Disagree }\end{array}$ \\
\hline $\begin{array}{l}\text { I do not think that my personal payment } \\
\text { information is kept safe when I use a } \\
\text { mobile payment service to pay for a } \\
\text { purchase }\end{array}$ & SECURE_1 & $10 \%$ & $29 \%$ & $32 \%$ & $19 \%$ & $10 \%$ \\
\hline $\begin{array}{l}\text { I am concerned about the security of } \\
\text { mobile payments }\end{array}$ & SECURE_2 & $43 \%$ & $34 \%$ & $14 \%$ & $8 \%$ & $1 \%$ \\
\hline $\begin{array}{l}\text { I am concerned about someone } \\
\text { intercepting my payment information or } \\
\text { other data if I use mobile payment } \\
\text { services }\end{array}$ & SECURE_3 & $33 \%$ & $37 \%$ & $20 \%$ & $9 \%$ & $1 \%$ \\
\hline
\end{tabular}

Categories were collapsed, combining Strongly Agree with Agree, and Strongly Disagree with Disagree. A Pearson chi-square test indicated that there is a strong, statistically significant relationship $(p<.001)$ between SECURE_1 (I do not think that my personal payment information is kept safe when I use a mobile payment service to pay for a purchase) and intent to use mobile payments (chi-square $=56.515, \mathrm{df}=4, \mathrm{p}=.000$ ). When asked what would encourage them to use m-payments in the future, nearly half of the participants who responded to the open-ended question (39 out of 79 participants, 49\%) indicated in some way that security concerns must be addressed before they would consider using mobile payments. In itself, this is a strong indicator that the sample was highly concerned with security. One participant wrote, "Too bleeding edge for something that could pose risk. Convenience is easy to see, but I'm willing to wait and see how secure it all really is." Another participant noted, "If there was a way that it was a lot safer and more secured then I would use it more." Another response was, "Just to make sure that the payment is secure, so my identity doesn't get stolen." Some other responses included, "More secure options," "More assurance of security," and "100\% guarantee of security and safety." These results suggest that the sample is highly concerned with perceived security risks of mobile payments. This is consistent with previous studies that found perceived security risk to be a barrier to acceptance (Cyril et al., 2008; Loilier, 2013; Zhou, 2011).

Additionally, one other theme emerged from the open-ended question where participants were asked to indicate what would encourage them to use mobile payments in the future. Eight (8) out of the 79 participants who responded to the question (10\%) indicated that they would be encouraged to use mobile payments if offered rewards or other incentives for using them. For example, one participant wrote, "Getting a reward after using the payment service a specific number of times." Other participants wrote, "Rewards program," and "Having unique specials." This result could indicate a unique opportunity for mobile payment vendors and retailers alike to encourage use of m-payments.

\section{DISCUSSION}

Findings from this research suggest that lack of awareness, lack of availability, and perceived security risks are all significant barriers to adoption of mobile payments. There was a statistically significant relationship between intention to use mobile payments and each of the following variables (AWARE_2, AWARE_3, AVAIL_1, and SECURE_1).

It was very clear from the results that the sample displayed a lack of awareness about mobile payments. While $88 \%$ of participants noted that they were aware that mobile payments existed, and were able to note a variety of $\mathrm{m}$ payment services, such as Apple Pay, Google Wallet, Android Pay, and others that they were familiar with, results from the survey also indicated that participants were less aware of specific services available for their own smartphone and how to use the necessary features. This points to an opportunity for m-payments vendors to provide more focused advertising and reinforces previous literature noting that mobile phone users need motivation to form 
positive perceptions about mobile payments (Wang, 2006). Results suggest that lack of availability is also a significant barrier to adoption of mobile payments. It was strongly indicated that participants did not think enough merchants participate in mobile payments to make use of them worthwhile. It should be noted that this may be a false perception predicated on an overall lack of awareness about mobile payments. As of March 2016, Apple Pay is available in over 2 million retail locations (Kharif, 2016), and Android Pay is available in over 1 million locations (Boxall, 2016).

The literature strongly suggests that perceived security risks could be a barrier to acceptance of mobile payments (Cyril et al., 2008; Kim et al., 2010; Loilier, 2013; Mallat, 2007; Misra \& Wickamasinghe, 2004; Zhou, 2011), despite claims of security experts that some forms of m-payments that use tokenization as a security feature could be considered more safe and secure than using a credit card (Sacco, 2014). This also could point to a lack of overall awareness and understanding of m-payment technology.

Our results recommend that the mobile payment industry needs to address these barriers explicitly and effectively for better adoption of payments through mobile devices. It is imperative that mobile payments players in the industry work toward educating consumers about the capabilities and secure nature of mobile transactions, in order to raise the awareness of these services. The mobile payment industry is still in a nascent stage of development with tremendous potential to grow and engage users to shape the future of this industry. Increased awareness and access to mobile payment options, and knowledge of the how transactions actually work would result in decreased perceived security risks and perhaps, increased usage of mobile payments. It will require persistent efforts on the part of this industry to reduce consumer anxieties and encourage better participation in mobile payment services.

This research has some limitations. First, the relatively small sample size does not allow for generalizability to a larger population. In addition, the distribution of ages of the participants was highly skewed toward younger age groups, likely due to using a convenience sample at a university for this exploratory study. This is important because younger participants may have very different views on technology acceptance than older participants. Future studies can sample a larger and more diverse population.

Future research should examine awareness of mobile payments and their perceived security risks at a more detailed level. Discrepancies in this study between a reported high overall awareness of mobile payments and lower reported levels of awareness in regard to understanding and using mobile payments on their own devices suggest that further research is warranted. It would be interesting to study and investigate ways and means to increase awareness and access to mobile payment options. In addition, there is evidence that mobile payments may indeed be more secure in many ways than using a credit card for purchases at retail locations (Sacco, 2014), though results from this study indicate that the sample perceived a high security risk in using mobile payments. These issues should be addressed in future work.

\section{ACKNOWLEDGMENT}

The material in this paper is based upon work supported by the National Science Foundation under Grant \#1515256. Any opinions, findings, conclusions, or recommendations expressed in this material are those of the authors and do not necessarily reflect the views of the National Science Foundation.

\section{REFERENCES}

Android. (2016). Android Pay. Retrieved from https://www.android.com/pay

Apple. (2016). Apple Pay security and privacy overview. Retrieved from https://support.apple.com/enus/HT203027

Bonderud, D. (2015). Mobile payment technology: Secure or subpar? IBM Security Intelligence. Retrieved from https://securityintelligence.com/mobile-payment-technology-secure-or-subpar/ 
Boxall, A. (2016). Everything you need to know about Android Pay. Digital Trends. Retrieved from http://www.digitaltrends.com/mobile/android-pay-guide/

Chandra, S., Srivastava, S.C. \& Theng,Y-L. (2010). Evaluating the role of trust in consumer adoption of mobile payment systems: An empirical analysis. Communications of the Association for Information Systems, 27, 561-588.

Chen, L. (2008). A model of consumer acceptance of mobile payment. International Journal of Mobile Communications, 6(1), 32-52.

Consumers and mobile financial services 2015. (2015). Board of Governors of the Federal Reserve System. 1-53.

Cyril, U., Guan Gan, G., Ademu, J, \& Tella, S. (2008). Modeling user trust and mobile payment adoption: A conceptual framework. Communications of the IBIMA, 3, 224-231.

Dahlberg, T., Mallat, N., Ondrus, J., \& Zmijewska, A. (2008). Past, present and future of mobile payments research: A literature review. Electronic Commerce Research and Applications, 7(2), 165-181.

Daştan, I. \& Gürler, C. (2016). Factors affecting the adoption of mobile payment systems: An empirical analysis, Emerging Markets Journal, 6(1), 17-24.

Ewing, D., Leberman, D., Mendelsohn, J., \& Milner, J. (2012). Understanding consumer adoption drivers: Insights from the McKinsey global mobile payments consumer survey. Retrieved from www.csi.mckinsey.com/Home/Knowledgebyregion/Global/ /media/extranets/consumer\%20shopp er\%20insights/reports/2012/global_mobile_payments.ashx

Hayashi, F. (2012). Mobile payments: What's in it for consumers? Federal Reserve Bank of Kansas City Economic Review. 35-66.

Jia, L., Hall, D., \& Sun, S. (2014). The effect of technology usage habits on consumers' intention to continue use mobile payments, Proceedings of Twentieth Americas Conference on Information Systems, Savannah.

Jia, L., Hall, D. \& Sun, S. (2015). Trust building in consumer learning process and its effect on consumers' behavioral intention toward mobile payments, Proceedings of Twenty-first Americas Conference on Information Systems, Puerto Rico, 2015.

Kim, C., Mirusmonov, M., \& Lee, I. (2010). An empirical examination of factors influencing the intention to use mobile payment. Computers in Human Behavior, 26(3), 310-322.

Kharif, O. (2016). Apple Pay locations reach 2 million, with Chik-Fil-A to come. Bloomberg Technology. Retrieved from http://www.bloomberg.com/news/articles/2016-02-04/apple-pay-locations-reach-2million-with-chick-fil-a-to-come

Loilier, L. (2013). Impact of mobile payments on the financial services sector, Blue Paper, GFT Group, 1-41.

Mallat, N. (2007). Exploring consumer adoption of mobile payments - A qualitative study. Journal of Strategic Information Systems, 16, 413-432.

MasterCard. (2014). Mobile payments readiness index. Retrieved from http://mobilereadiness.mastercard.com/theindex/

Misra, S.K. \& Wickamasinghe, N. (2004). Security of a mobile transaction: A trust model. Electronic Commerce Research, 4, 359-372. 


\section{Issues in Information Systems \\ Volume 17, Issue III, pp. 20-30, 2016}

Sacco, A. (2014). Security, payments experts talk Apple Pay. CIO. Retrieved from http://www.cio.com/article/2837400/payment-processing/security-payments-experts-talk-apple-pay.html

Schierz, P., Schilke, O., \& Wirtz, B. (2010). Understanding consumer acceptance of mobile payment services: An empirical analysis. Electronic Commerce Research and Applications, 9(2010), 209-216.

Shin, D.H. (2010). Modeling the interaction of users and mobile payment system: Conceptual framework. International Journal of Human-Computer Interaction, 26(10), 917-940.

Srivastava, S., Chandra, S., \& Theng, Y. (2010). Evaluating the role of trust in consumer adoption of mobile payment systems: An empirical analysis. Communications of the Association for Information Systems, 27, 561-588.

Wang, A. (2012). A preliminary model for mobile payment acceptance, International Journal of Mobile Marketing, $7(2), 37-51$.

Wang, A. (2006). When synergy in marketing communication online enhances audience response: The effects of varying advertising and product publicity messages. Journal of Advertising Research, 46 (2), 160-170.

Zhou, T. (2011). The effect of initial trust on user adoption of mobile payment, Information Development, 27(4), 290-300, DOI: 10.1177/0266666911424075 